\title{
sciendo
}

DOI: 10.2478/jolace-2021-0018

\section{An investigation of the reading culture: the role of libraries to promote reading culture in Pakistan}

\author{
Muhammad Asif \& Liu Yang \\ Hunan Normal University, Changsha, China \\ asifanu@hotmail.com
}

\begin{abstract}
The library's goal is to promote the culture of reading. Not only does the library promote the culture of reading, but also it facilitates access to books for those who love reading. Thus, through the library, its visitors can enjoy not only their lives, but also it allows them to spend their time intellectually. This program has been designed to help people discover the joy of the written word. The primary goal of fostering a love of reading among library patrons is to make it an enjoyable and rewarding pastime. As a result, it is critical to raise awareness about the value of reading for pleasure rather than only learning material for tests and encourage students to make reading a habit. Library Week, which is held each year during the academic session in high school, is one of the ways that libraries can help spread the word about the importance of reading and healthy reading culture. The relevant literature has been assessed in light of the topic by searching both published and unpublished relevant research works. Tylor and Francis Group, ERIC, Emerald, Elsevier, LISA, LISTA, ProQuest Research papers, and Wiley Online Library are addressed as relevant databases. The current study's findings may also aid in better planning school library services and dealing with the required, complicated, and ever-increasing requirements for book selection, acquisition, and integration. The findings are also aid in the modification and enhancement of educational policy.
\end{abstract}

Key words: reading habits, academic reading, internet era, lifelong reading

\section{Introduction}

Reading is not usually the most useful of the four language abilities, but it is a crucial component in vocabulary enrichment, character development, and improved academic success (Chokron, 2000). It is the foundation for developing and maturing into a wellorganized individual. People study for various reasons, including enjoyment, expertise, need, record-keeping, research, and so on. Reading is described as the activity of looking at and comprehending the meaning of a piece of text by decoding the letters or symbols that comprise it up (Hooper, 2005). Reading is a remarkably participatory activity. This interaction occurs via the recreational activity of analysing, a complex interaction of nearby stage bottom-up strategies concerned with the identity of meaning from the level of phrase upwards and increasingly global tiers of top-down, higher cognitive stratagems, and historical knowledge (Applegate, 2004). There are several abilities associated with reading that are necessary for anyone participating in reading to comprehend a particular text or piece of writing. Reading, in general, entails both word pronunciation and comprehension of the information. They complement one another - if one is the body, the other is the soul and quintessence of it. Reading habits that are beneficial and meaningful aid learners in acquiring desired and valuable information. Good reading habits provide pupils with a powerful tool for success in life. Thus, reading should be a priority for everyone - children, teachers, and parents alike - 
since reading as a component of language significantly impacts a child's whole development, including his capacity for thought and cognitive growth.

Dorothy (2002) asserts that reading is a holistic, integrative activity that begins with the reader and spans the following domains: emotive, cognitive, and perceptual. The aesthetic realm is comprised of our thoughts, feelings, and emotions. For example, if we have negative sentiments about anything, these negative feelings will very certainly impact how we perceive what we read. Our emotions might also affect what we choose to read. Perception is described as the capacity to give meaning to experiences or arrange inputs in a field. How we arrange inputs is highly dependent on our prior experiences and sensory receptors. Visual perception is the most critical aspect of the process of reading. The reader's eye movements influence the reader's perception. Cognitive domain: comprises reasoning and understanding abilities. Reading would be challenging for someone who has problems thinking; for example, Readers who have misperceptions will also have misconceptions about their notions, and it would be difficult for them to read. When it comes to learning behaviour patterns, culture may be described as an integrated system of acquired patterns that are typical of the people of a community and are not the consequence of biological heredity. Reading culture suggests that reading is a fundamental aspect of culture and habit that must be shared and highly valued in society, denoting that reading is necessary for obtaining knowledge as required in daily life. Reading culture is a subset of reading culture. A person must have the capacity to identify and access information inaccessible books or information items and assess and use such information. A reading culture cannot be established just based on one's ability to read and write. When it comes to creating a reading culture, reading must play a substantial part in a person's day-to-day life and become a habit. A reading culture is defined as a style of life characterized by the habit of reading widely and deeply in the context of this discussion.

Gambrell (2011) proposed seven criteria for motivating pupils to read in order to increase reading motivation. The following two rules emphasized parents' role in instilling a reading habit in their children: students are more motivated to read when they have ample opportunities to engage in sustained reading and "access to a broader range of reading materials. These criteria, which include offering a range of reading resources at home and engaging pupils in reading, are beneficial in increasing reading motivation among students. (Dent, 2013) added that more than half of students use libraries to accomplish their schoolwork, learn much more about the world and work freely by socializing with their classmates. Academic, social, and cultural reasons are the most often cited reasons for visiting a library. Literature has shown that the habit of reading may be developed at a young age. Early contacts between parents and their children positively affect their children's reading abilities (Dodici, Draper \& Peterson, 2003). Between 2001 and 2006, researchers Netten, Voeten, Droop, and Verhoeven (2014) observed a substantial drop in reading proficiency among Dutch schoolchildren. According to Kush and Watkins (1996), academic and recreational reading among youngsters has seen significant declines. Linnakyla, Malin, and Taube (2004) identified the variables that contribute to reading decrease in industrialized nations with high literacy levels, such as Finland and Sweden, and presented evidence to support their findings. The male gender, multiple siblings, and a poor socioeconomic background are all significant variables. Clark and Akerman (2006) compiled statistics on reading for enjoyment in the context of industrialized nations, noting that teens read an average of two novels per month on average. It has been shown that the desire to read declines with increasing age. Boys spend just 3 to 4 
hours a week reading for enjoyment and entertainment, but girls spend much more time reading than boys.

The digital paradigm's quick technical advancements seem to be causing significant alterations in reading habits. Due to the increasing need for digital access to full-text content, libraries have adapted and become hybrid institutions. In recent years, scholars worldwide have focused on the influence of digital reading formats on current reading practices. Several studies have been conducted over the past decade to determine the reading habits of current readers in a digital world. E-reading, reading in the digital age, the influence of ICT on book consumption patterns, print vs. digital, and the evolving role of libraries in the new media landscape have all been extensively researched (Bodomo, Lam \& Lee 2003; Ahuja, Mishra \& Goyal, 2010; Cull, 2011; Cumaoglu, Sacici \& Torun, 2013). Students' reading habits in a digital age have recently become a hot topic in academia. Children, adults, men, and women have all been studied to see how they vary from one another in their reading habits in Pakistan (Awais \& Ameen, 2013; Ahmed, 1964). There was, however, no local published literature on the "reading tendencies of young" (as stated by this research) in a digital context. There was just one research that came close to this one. It looked at how researchers used digital information to conduct their study. However, articles and conversations about the shifting reading habits in digital environments may be found in print and online media, such as daily newspapers, government publications, and websites. Discussions on reading habits are dominated by the belief that modern technology such as smartphones and iPad are to blame for declining reading habits (Daily Time, 21 January 2014).

They feel that the overuse of technology is a significant factor in the collapse of the young reading culture. According to Pakistan Today (11 July 2011), the book reading habit is on the downturn. Most pupils choose to read books in print format rather than digital format. Gallup Pakistan (2011) conducted a poll and discovered that just 28\% of Pakistanis claim to read books (other than textbooks), down from 46\% in 2002. However, there are doubts regarding the sample's representativeness for generalizing the findings. The evolution of reading habits in the modern age is a fascinating issue for debate among library science professionals, educators, and members of the learned community. Numerous research on reading habits is available in Pakistan. Much has been published on the reading habits of newspaper readers. However, the widely disputed worldwide issue of reading behaviour in a digital context has been primarily ignored in local literature. There has been no empirical study on reading behaviour in this situation. In this regard, it was appropriate to do an empirical study on this topic in Pakistan. As a result, a survey was done to evaluate the overall perception of present reading trends. Given the significance of the issue and the significant changes in student reading behaviour described by researchers from other nations in a paperless and digital environment society, it was thought necessary to explore reading trends in Pakistan, especially in academic contexts. It is most likely the first empirical research on this topic in Pakistan, and it will make an essential addition to the LIS literature in Pakistan. Understanding reader behaviour will aid in the improvement of library services. Furthermore, it is an exploratory baseline study that will pave the way for future researchers.

The relevant literature has been assessed in light of the topic by searching both published and unpublished relevant research works. Tylor and Francis Group, ERIC, Emerald, Elsevier, LISA, LISTA, ProQuest Research papers, and Wiley Online Library are addressed as relevant databases. The following objectives are included in this study: to define the concept of reading culture, to investigate the causes of poor reading and the need to improve them, to suggest 
important roles libraries can play in improving and promoting reading culture in society, to focus on the role of libraries on reading in the twenty-first century, and to examine the reading habits of university students in Pakistan.

Even in industrialized and high-literacy nations, children's reading is declining. As a result, it was thought to investigate the elements, particularly those connected to children, families, and teachers, that contribute to youngsters' reading habits. Unfortunately, the younger generation is less likely to develop a love of reading. The most significant influence of technology and other amenities has been on pupils' reading habits. Research like this would be a valuable addition to local literature and would assist librarians in improving library services. Teenagers are our next generation and improving this generation's reading habits at the school level can assist in delivering a better product to universities and higher education institutions. The current study's findings may also aid in better planning school library services and dealing with the required, complicated, and ever-increasing requirements for book selection, acquisition, and integration. The results will also aid in the modification and enhancement of educational policy.

\section{Literature review}

It has been a significant issue in numerous nations throughout the globe to promote a reading culture, but despite all of these efforts, one common danger emerges: no country is pleased with the number of engaged readers existent among its people. In most nations, it is believed that the approaches and teaching techniques used to increase reading must be repeated repeatedly to bring people and books together in a long-term, mutually beneficial relationship. According to Eisemon (1997), if the current rate of reading continues uninterrupted, the number of illiterates will continue to rise in the future. It is noted by Makenzi (2004) that illiteracy, which is the polar opposite of literacy, is challenging to quantify. While statistics on the world's illiterate populations are relatively easy to obtain, little is known about the millions of literate adults who rarely pick up books or magazines, and little is known about the millions of schoolchildren for whom reading has come to mean textbooks little else. Because there are so many different types of reading, it is still difficult to pinpoint what is causing this occurrence. Furthermore, reading habits differ significantly depending on the age group, educational level, and socio-cultural background of the reader.

The creation of a reading culture among their population has been a top priority for governments all over the globe for many years. The United Nations Educational, Scientific, and Cultural Organization (UNESCO) said in 1994 that constructive participation and the growth of democracy depend on adequate education and open and unfettered access to knowledge, ideas, culture, and information. It is impossible to ignore the efforts being made to promote a reading culture. In his book Makenzi (2004), the author presents reading as a tool for attaining lifelong learning and reading competencies. Wawire (2010), on the other hand, thinks that reading is vital since it is essential to the growth of the individual. In order to participate fully in contemporary society, it is necessary to improve the overall quality of life while also providing access to culture and cultural heritage. Citizen empowerment and emancipation are facilitated by reading for pleasure. It draws people together in a positive way. Book reading is crucial because books are the key to unlocking the world, both in the actual world and in the fantasy realm. As a result, it should be promoted among the wider community. It has been shown via research that persons who read for assessments eventually become illiterate. Rosenberg (2000) further said that if students do not have the chance to read extensively, what 
they learn in the classroom will not be reinforced, and the quality and performance of the educational benefit will be undermined. Pupils/students will not acquire abilities such as finding, choosing, organizing, manipulating, analysing, evaluating, and digesting information if they do not engage in extensive reading.

Numerous research on reading habits and reading culture in various nations have been undertaken. Goulding mentioned the recent introduction of reading promotion plans in UK public libraries, which involve activities from partner groups. Librarians must first understand why people read books, the needs it fills, and their function in people's lives to remain effective in this area. Public libraries in the United Kingdom are also proactive in addressing the needs of non-readers, especially in impoverished communities, by promoting adult basic skills development and introducing the notion of community librarianship. Lijuan discussed reading promotion programs in Hong Kong and Macao.

Additionally, the researchers suggest enhancing reading activities and marketing based on their experiences with public libraries. Mc Swain at Salisbury Library Services in South Australia established a comprehensive program over four years that focuses on seven components to encourage all age groups in the community to read. Several of these components depend on relationship development. Palmer offers numerous ways of encouraging girls and boys to read. Smith and Young discussed how academic librarians might encourage users to read by using displays, training, programming, linking with other libraries, broadening genre concepts, and building readers' advisory abilities. Trott and Elliott recognized and emphasized many challenges to such attempts, including funding restrictions, personnel concerns, and a low priority for encouraging reading in university libraries. Doiron's research focused on the motivation of reading habits via information books in the literacy process. Shehu and Shehu's research focused on the development of reading culture and readership among Nigerian nation users. Fabunmi and Olayinka performed a study of secondary school students to discover the reasons for low reading culture and propose strategies to improve reading culture among students. A professional librarian should be hired. It is disappointing that none of the secondary schools examined had a professional librarian. A professional is required for a strong library program. He is the creator, organizer, and initiator of several programs.

Burgess (2005) discovered that mothers' awareness of accessible children's books, academic level, and familiarity with print materials were related to children's reading levels. It was also said that women who were more interested in watching television and less engaged in reading were ineffective contributors to their children's academic attainment. Hansen (1969) observed that although a favorable literacy environment supplied by parents was significant, the educational level and employment of the parents had little influence on children's reading development.

Lyytinen, Laakso, and Poikkeus (1998) agreed that the mother's education, literacy, and reading engagement habits significantly impacted 2-year-old children's lexical and syntactic development. In this regard, the father's education was shown to be negligible. Hartas (2012) showed in a UK-based research study that mothers' educational level was a key influence in their children's reading and writing. However, Yusof (2010) said that the father's qualification was related to reading interest in children. Those from lower socioeconomic backgrounds read less for pleasure than children from higher socioeconomic backgrounds (Clark \& Akerman, 2006). Linnakyla, Malin, and Taube (2004) revealed that male gender, poor social and 
economic standing, and children's lower reading engagement were significant reasons for the fall in reading.

Factors affecting reading habits

Factors responsible for poor reading culture

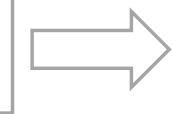

Commercialization of Education Lack of Govt. Policies (Absconding role of state towards Higher Education)

Corruption

Noise culture

Malpractices attached to earn "quick money"/ wealth

Lack of reading language

Administration's poor attitude towards libraries

Fig. 1: Factors affecting and responsible for reading habits among children's and university students

Farver, Yiyuan, Eppe, and Lonigan (2006) discovered a significant association between a family's social and economic status (SES) and a child's reading development. The size of the family and the amenities provided at home had a significant impact on children's reading. According to Hartas (2012), family income has a statistically significant relationship with pupils' reading, writing, speaking, and listening skills. When compared to impoverished children, wealthier children performed better in all four criteria. Hung and Marjoribanks (2005) discovered that parents who lacked economic capital could not establish an appropriate learning and reading environment for their children. In contrast, Scher and Baker (1994) discovered that first-graders had a good attitude toward reading regardless of their socioeconomic level, and Yusof (2010) concurred that economic status was not connected with children's literacy proficiency.

According to Camp (2007), the majority of the youngsters were inspired by the reading of their fathers and mothers who were assisting them with school-related activities and reading aloud to them. In research undertaken by Feitelson and Goldstein (1986) while examining Israeli families' reading behaviours, it was shown that practically all families read to their children at least half an hour every day. They read at set times, mainly in the evenings before going to bed. Hartas (2012) found that mother reading pleasure and motivation were substantially related to children's reading aptitude. Furthermore, the mother's reading habit aided the children's reading, writing, listening, and speaking abilities. The frequency with which mothers read has a major impact on their children's reading development. Kim (2009) discovered that reading at home was linked to a child's ability to read. In addition, the author noted that the children's vocabulary and phonological experiences improved as a result of reading at home. It was found that children who had been exposed to reading by their parents were more interested in books. While most children shared reading with their moms, Clark, Osborne and Akerman (2008) found that males preferred to share reading with their dads more than girls. For the vast majority of the kids, their moms were more enthusiastic about 
reading than their dads. According to Greaney (1986), the influence of parents in the development of reading habits and reading abilities in their children was investigated in an experiment. The following six elements were found as being important in the development of reading habits in children: In addition, parents' verbal interaction with their children improved cognitive and language skills, 2) parents' reading interest had a positive impact on their children's reading development, 3) parents' reading to their children had a significant impact on early literacy, 4) access to more diverse materials was also considered a positive indicator of reading development, 5) providing a reading environment and reading opportunities at home could assist parents in supporting their children's reading development. 6), parent-child reading, in which parents read aloud to their children and discussed their reading experiences with them All of these factors were regarded to be important in the establishment of a reading habit in youngsters.

High, Hopmann, LaGasse, and Linn (1998) conducted research to determine how sharing books and motivating reading before bedtime by two groups of families of diverse ethnic and socioeconomic backgrounds affected reading development. It was made accessible to the parents' books and instructions on how to share these books with their children. They were looking forward to exchanging books and considered it to be their favorite pastime. In this respect, Kush and Watkins (1996) recommended that the school collaborate with parents to build readers' attitudes about reading successfully. According to Lyytinen, Laakso, and Poikkeus (1998), reading with fathers was connected with children's early interest in reading. Nichols (2000) revealed the findings of review-based research that has been done to investigate the reading habits of Australian families before their children. Fathers were shown to be less concerned about providing reading exposure to their early children than mothers. According to Ogunrombi and Adio (1995), the attitude and support of parents toward their children who were attempting to build a better reading habit was thought to be essential. Shapiro and Whitney (1997) concluded that parental support was the most critical factor in distinguishing between eager and hesitant readers. When school teachers have a positive attitude toward reading, their reading enjoyment and recreation, familiarity with children's interests and literature, and the ability to recommend material based on their interest, the love of reading among school children increases (Duffy, 1967). Robinson (1979) lamented that schoolteachers did not demonstrate themselves as role models for their students (Duffy, 1967). They were not excellent readers in their own right. According to Oyelude (2013), the school leadership should significantly encourage the use of the library by teachers and the development of a reading habit among them.

Employing data from McKool and Gespass (2009), they investigated the association between teachers' reading habits and instructional tactics in the classroom. A total of 65 elementary school instructors were polled for this study. The survey findings revealed that only a tiny percentage of instructors read for pleasure daily, even for 10 minutes, while the majority of them were involved in other activities. In addition, it was shown that instructors who read for pleasure outside of school for more than 30 minutes used more creative tactics, such as literary groups, book recommendations, introducing continuous silent reading, and leading reading sessions. The instructors who emphasized reading believed that instilling a reading habit in kids was more essential. Surprisingly, the research found no difference in the ability to motivate students for pleasure reading between instructors who read for pleasure and those who did not read for pleasure, according to the findings. The school instructors who said that they read for pleasure most of the time used a range of best practices in the classroom 
to encourage students to develop a reading habit. These practices included activities such as reading aloud, continuous quiet reading and suggesting intriguing books to the reader. $\mathrm{A}$ schoolteacher must develop a reading culture in students by proposing reasonable amounts to them; she/he must be knowledgeable about the book, the author, and the genre (McCuthen, et al., 2002 as cited by McKool \& Gespass, 2009).

Burgess et al. (2011) investigated the association between schoolteachers' reading habits, their understanding of children's literature, and their involvement in promoting reading among school students. The research included 161 fifth-grade instructors from around the United States. The research concluded that the function of the schoolteacher in developing pupils' reading ability was significantly impacted by his or her reading ability and understanding of children's literature. Additionally, it was proven that instructors with a more excellent grasp of children's books used better literacy methods. Regrettably, we depend heavily on picture books and novels rather than narrative text to encourage children's voluntary reading habits. We should strike a balance between fiction, narrative, and informational literature. To accomplish this, school instructors must be experts in children's literature and knowledgeable about global literature publication, which may aid in developing children's leisure reading habits (Morrow \& Gambrell, 2001 as cited by Doiron, 2003).

The problematic of reading in Pakistan

Students at various educational levels have been studied to determine their reading habits, preferences, and trends. This includes primary school children, secondary school students, and undergraduates (Ahmad, Malik \& Azeem, 2014; Soroya \& Ameen, 2016). Insufficient research has been done on how schoolchildren's information literacy abilities affect learning (Batool \& Mahmood, 2016). Other professional groups were studied in Pakistan, including information professionals (Naveed \& Ameen, 2015), journalists (Shahid, 2015), and academic members, as well as their reading habits (Zia \& Samreen, 2017). Gender disparities among university students (Dilshad, Adnan \& Akram, 2013), the influence of technology (Ahmad, Malik \& Azeem, 2014), the function of school teachers (Jabbar, 2015), and the importance of libraries (Mahmood, 2004) in promoting reading habits have been documented in the literature. There are three key stakeholders in a kid's reading habit: the child, family, and a teacher. A few studies have examined the function of teachers and librarians in developing reading habits among children, but the involvement of families and children is not addressed in local literature (Jabbar, 2015). To comprehend the phenomena and derive practical consequences, it is necessary to examine all three contributing variables: children, families, and teachers. As a result, research is urgently needed to fill the vacuum in the literature.

According to Akbar (2020), a survey conducted by an international non-governmental organization has shown that Pakistan's reading culture is rapidly declining; this is true not just in educational institutions but also at the grassroots level. The results of this poll are pretty intriguing and thought-provoking - unquestionably an eye-opener and a wake-up call for our policymakers, educators, and parents, among other stakeholders. It has been reported that a kid in the fifth grade is unable to read books at the third-grade level or any books other than those produced by provincial textbook boards, who are presumably responsible for creating high-quality textbooks for students at the same level as themselves. In a similar vein, students pursuing a bachelor's or master's degree at a higher level cannot read texts from the secondary level. Perhaps more crucially, the instructors who have been assigned to teach post-secondary courses lack the necessary competence and abilities to teach books at an intermediate level without the aid of supporting materials. The results of this study, when analysed at their core 
and evaluated against current ground realities, speak eloquently about their validity and authenticity and may be safely applied to both the commercial and governmental sectors in an equal manner. When it comes to pronunciation of Urdu and English, which is an essential communication component, the quality at the school level is clearly below average, particularly in rural institutions. Rather than being a pure class activity, instructors turned reading for understanding into a one-dimensional cramming exercise, with the only goal of achieving excellent scores as a result. In the case of extended reading, there is no worry or niche for it, namely, reading for pleasure or learning general ideas and subjects. This bleak picture brings home the stark fact that the quality of education is at an all-time low, despite claims to the contrary that the amount of education is expanding. Several factors contribute to this shortfall or disproportion, and policymakers should examine their actions to determine the root cause of the problem.

Most of our instructors lack mastery of the subject matter and the necessary abilities to teach in classrooms properly. For many language instructors, reading comprehension is a long way from their grasp. They become reliant on dictionaries, which is a bad reading habit in and of itself. Prediction and meaning making are two of the essential skills for language instructors, yet they lack pedagogy. Academics in humanities, a critical skill at the post-secondary level, are poor in their capacity to critique. In their field of expertise, they cannot balance and measure the substance and subject matter. Student rigidity and conditioning is the second loophole in this respect. Assignments or test time merely compel them to put their feet up and read. Lack of additional reading resources in schools has a detrimental effect on students' reading habits and makes it harder for them to use the library effectively.

Another important cause is the cramming environment that pervades our testing and assessment systems. It is nourished and nurtured obliviously by our flawed examination system and religious institutions. It has harmed and suffocated the germination and development of creative and critical reading even more. Furthermore, it is hardly exaggerated to assert that reading at the communal level has plummeted. A sophisticated educationist observed mockingly but accurately that most of our so-called educated class reads one book carefully and exhaustively, namely, Facebook. Unfortunately, pupils do not read for the goal of developing their brains or for enjoyment; they open books for test reasons.

Additionally, books are expensive, and many parents are impoverished and unable to pay the high cost of books for their children. Most students can only acquire a few textbooks out of the whole list of required materials. In secondary schools, a lack of physical amenities such as tables, seats, and enough lighting for reading is also a concern. The space required to read and study is a rare luxury that not all students can afford. Additionally, instructors lack familiarity with children's literature. Many of them cannot expose pupils to the vast array of accessible literature, and they may be unaware of the impact their teaching techniques have on students' attitudes about reading.

A study was conducted to ascertain the gender disparities in the reading habits of Pakistani university students. A questionnaire was sent to 1050 students of both sexes from three institutions in Punjab province. The findings indicated that male and female students' reading preferences varied considerably, depending on their goal, taste, available study time, and other aspects. Female students, on average, had a more favorable attitude toward reading than male pupils. Academics at universities are urged to take a proactive role in inspiring, directing, and managing students toward developing excellent reading habits, especially among male students. Libraries at higher education institutions should be well-stocked with various 
printed and electronic reading resources and should provide a conducive reading environment for students (Dilshad \& Akram, 2013). Another research evaluates the reading habits of learners at the University of Sindh in Pakistan in both English and their mother tongue (L1). It examines the differences and similarities in the reading habits of Urdu and Sindhi learners. The results affect the comprehension and development of reading habits of college students in Pakistan, particularly those studying in a second language (L2). context (Ansari \& Umrani, 2016).

Research of Pakistani millennials' reading habits is conducted by measuring their views about reading in a digital context. Researchers showed that millennials are more likely to utilize electronic reading materials than older generations. On the other hand, research has revealed that the aim of reading may influence the method of reading. Open access e-content and open access content may also play a role in the rising usage of e-content since free websites have been the favored route for millennials to acquire reading material. Search engines like Google and social networking sites such as Facebook were also utilized to obtain relevant information and consume electronic material. The digital world influences people's reading habits, which must be taken into account by instructors, practitioners, and the general public (Soroya, 2020). Another study was conducted to see what characteristics are most effective in encouraging pupils to read. Children's reading habits are encouraged in households where parents play an essential role, as shown by this research. This reading habit is instilled in students by their teachers and parents during their lives (Adnan \& Akram, 2016). To convey our understanding of the world, we must learn to read. Decryption is performed employing this skill, and in other words, the results of this research are based on the reading habits of students who have not yet earned a bachelor's degree. According to the findings, university students still choose paperbacks when reading for pleasure or academic purposes (Ghaffar, 2018).

According to the Pakistan Education Statistics (PES), in 2015, Approximately 60 percent of children aged ten and older were literate; the process of learning to read requires time and effort - both in and out of the classroom. Communities all around Pakistan are often deprived of access to reading materials. The Pakistan Reading Project, funded by the United States Agency for International Development (USAID), aims to improve the reading skills of 1.3 million children across Pakistan by collaborating with teachers and engaging communities in order to promote a culture of reading and provide books and other reading materials directly to children. USAID's \$165 million Pakistan Reading Project assists provincial and regional education departments in improving classroom learning environments for reading, improving policies and systems for reading, and building community-based support for reading in Pakistan. The United States Agency funds the project for International Development (USAID). Academics and legal experts in Pakistan and the United States have stated that intellectual property rights (IPR) stimulate economic growth in Pakistan because they are designed to protect and encourage innovation and creativity, which are essential factors in generating economic activities. Intellectual property rights also assist the industry in creating new jobs and competing in the international market (Ali, 2017).

\section{Role of libraries in promoting reading culture}

Libraries may play a critical role in encouraging reading culture among readers by implementing a wide range of strategies (see Tab. 1). 


\begin{tabular}{|l|l|}
\hline Providing platforms to access resources & Provision of library hours in curriculums \\
\hline Atmosphere matters lot & Interaction with users \\
\hline $\begin{array}{l}\text { Access to the correct information and } \\
\text { services }\end{array}$ & The reward for the best reader \\
\hline Creating effective strategy & $\begin{array}{l}\text { Encourage users to read and write through } \\
\text { social media }\end{array}$ \\
\hline Creation of reading groups & Use library collection \\
\hline Making effective campaign & publicity and marketing \\
\hline Organizing workshops & Read what Students are Reading \\
\hline Mobile libraries & Create and keep a record of every user \\
\hline Virtual author visits & Use of web and self-assessment tools \\
\hline Provision adequate funds & $\begin{array}{l}\text { Reconstruction of services \& reading for } \\
\text { pleasure }\end{array}$ \\
\hline
\end{tabular}

Tab. 1: Strategies for encouraging reading culture

The Internet and information and communications technology (ICTs) have impacted several facets of human existence, including reading habits. The prominent role of ICTs, particularly the usage of e-resources, has significantly altered the fabric of the new generation's reading habits and has also impacted how students use library resources (Chettri \& Rout, 2013). Students spend most of their time in front of the television, playing computer games, using the X-box, browsing the web, and engaging in other social media activities (Davidovitch \& Yavich, 2016). According to Weller (2011), technology has taken over our life, culminating in the technological revolution. This study's goal was to investigate the impact of social media on university students' learning and social change behaviour (Kim, Karatepe, Lee \& Demiral, 2018). Because of the growing importance of social media in teaching and learning, this study's goal is well-supported by the existing research. There is a favourable influence on students' profound learning experience when social media is used in education, according to Stathopoulou et al. (2019). Students and instructors alike benefit from the use of social media throughout the learning process. Teachers and parents have been warned that allowing pupils to overuse social media might negatively affect their students. According to the results of this research, social media has both beneficial and bad effects on students' learning. A balanced approach is advocated when utilizing social media apps (Lee \& Suzanne, 2017).

Balakrishnan and Gan (2016) discovered that student enrolment has a favourable effect on learning effectiveness and that learning motivation has a beneficial effect on students (Law, Geng \& Li, 2019). Another research discovered that developing social media apps enable students to utilize social media for learning in ways that are tailored to their learning styles. While scholars have researched social media to identify its potential use for technical communication practitioners (Kimme, 2014), social media has more significant implications for students in classrooms (Kaufer, Gunawardena \& Tan, 2011). Bernadette Longo mentioned in her research paper about developing a case study on technology that social media is an intrinsic aspect of the enormous and complex social networks that comprise human technologies (Longo, 2014). In social media, influential individuals are often those who significantly impact their peers' behaviour, opinions, and interactions (Bruning, Alge \& Lin 2018: Nair, Manchanda \& Bhatia, 2010; Asif, et al. 2021). Social computing enables study on social influences on behaviour and focuses on social behaviour (Wang, Aribarg \& Atchade, 
2013). The study of a social network is a widely used approach for determining the social impact of social media users [Liang et al., 2015; Schlereth, Barrot, Skiera \& Takac, 2013]. Social media may be a critical component in book promotion. Social media platforms may be used to encourage book reading. Writers and readers may start debates about books, which will draw the attention of social media users, who will ultimately be enticed to read them.

According to Shaikh, (2019), Professor Dr. Husnul Amin, Executive Director, Iqbal Institute of Research and Dialogue, International Islamic University, Islamabad (IIUI), "Recently, a student under his supervision revealed in her research thesis that students enrolled in Islamabad-based universities spend approximately 6-9 hours (74 percent) of their daily time on social media (Facebook, Twitter, WhatsApp, Instagram, etc.). He said that valuable time was being squandered on social media, noting that students often opted for rapid reading, readingin-bullets, and graphics, among other strategies, to avoid the original text(s)." According to Faran Shaikh, a student at Karachi School of Business \& Leadership, "books are no longer attracting as many people as they once did owe to technological advancements." Students prefer to watch rather than read since seeing does not need as much work to comprehend." "In the early 1990s, since he was a student in Lahore, there were several public libraries and bookstores with reasonably priced books." He said that the tendency has shifted due to the drop in reading habits brought about by social and electronic media and the absence of a bookshop in that neighbourhood. "Nowadays, pupils choose for the spoon, surface, or brief reading, and that too on social media platforms fascinated with the concept of 'quick-to-share' content online," Dr. Kamal said.

This change is altering not just our way of life but also our children's reading habits. Reading is defined in this research as reading with eye contact to satisfy an individual's information needs for any purpose, whether on paper or screen. However, reading via audio/talking software or braille is disregarded in this instance. With the growing use of digital devices, reading is increasingly becoming a screen-based activity rather than a paper-based one (Davidovitch \& Yavich, 2016). Libraries, too, are adapting to these developments by becoming hybrid to meet the need for full-text access to digital information resources (Soroya \& Ameen, 2018). Technological advancements changed students' reading habits, shifting them away from print books and toward e-books and e-readers, owing to the advantages of conventional books, such as mobility, 24/7 internet accessibility, and cost savings (Jamali, Nicholas \& Rowlands, 2009).

Additionally, Amazon's Kindle brought the goal of the portable digital library closer to reality by increasing the speed of downloads and storage capacity _up to 200 books_ for academic and public libraries. With the advent of these services, several libraries are now offering electronic book circulation and limited download choices to their clients (Ferguson, 2008). It is critical to design library services in response to new reading formats and fast technological progress.

When it comes to reading preferences, trends, attitudes, and habits, several exciting study topics have come to light due to this transformation. Many challenges and tasks confront educators nowadays because of the recent advent of new technologies that are stealing away kids' reading time (Kavi, Tackie, and Bugyei, 2015). New technology may play a role in influencing reading habits and the influence of digital reading devices on the reading practices of teenagers (Pattuelli \& Rabina, 2010). There is always a need for segmentation in marketing since we cannot provide all items to all clients. Digital immigrants and digital natives and their reading habits and interests must be studied to build user-centred library services and 
encourage reading culture. However, several authors have classed generations with a minor discrepancy in birth years, according to Soroya and Ameen (2020), who found that the following generational categorization is generally accepted: Generation X (Born between 1965 and 1980), also known as digital immigrants; Generation Y (Born between 1981 and 1996), also known as digital natives; and Generation Z (Born between 1997 and 2018). (Born between 1996 and 2015). Generation Z (born in the late 1990s) has unique traits and cannot be viewed as a homogeneous group since they are significantly advanced information communication technology users.

To provide library and information services tailored to its users' needs, it is essential to collect data on their reading habits and preferences. There have been very few studies in Pakistan looking at how reading habits evolve. Student reading habits have seen dramatic shifts in recent decades, making it a fascinating issue for experts to study. According to a recent survey, kids' reading habits in the Y Generation have shifted dramatically over the previous decade. Increased reading time (whether in print or digital) results from the proliferation of digital reading material and e-reading devices (Soroya \& Ameen, 2016). Despite this, very little is known about Generation Z's reading habits in Pakistan. The reading choices of Bahawalpur secondary school students were examined by Hussain and Munshi (2011). As part of their research, Awais and Ameen (2013) examined the reading habits of elementary school students (Generation Z).

On the other hand, studies on Generation $\mathrm{Z}$ fail to address the influence of electronic reading on this generation's reading habits. Local literature and library services might benefit from the findings of such research. To produce a better product for higher education institutions, it is necessary to enhance the reading habits of teenagers at the school level. Using the findings of this research, school librarians may be able to better plan their collection development and acquisition processes in light of the ever-increasing and more complicated requirements for e-book content. Revisions and enhancements to educational policies will be made possible because of the results.

Mahmood and Saeed (2014) examined digital information in order to ascertain researcher conduct. The findings indicated a tendency toward electronic information usage, as all respondents utilized digital information for research purposes, and there was not a single research fellow who did not use digital information throughout their study. As a result, most researchers used digital data for two to three years (33). The authors suggested that the availability of the HEC digital library increased the use of digital information. Respondents said that they often utilized digital data for academic purposes.

Additionally, participants said that they had solid digital information abilities. The digital revolution has created a whole generation of digitally savvy individuals. This generation is comprised of individuals born during the 1980s and early 1990s. They are referred to as millennials, echo boomers, internet generation, iGen, and net generation (Business Dictionary.com, 2014). Net Generation will grow and superimpose its culture on the rest of society via digital media. Educators over the globe are emphasizing that the current generation is distinct from the previous one and should be addressed differently. Luis M. Proenza, president of the Institution of Akron, stated unequivocally, "The time has come for some profound reforms to the university, our pedagogical model, our operational model, and our interaction with the rest of the world." However, we must listen to these Net Generation youngsters to develop a plan ahead (Tapscott, 2009). Among all the revolutionary changes, the younger age has seen the most dramatic shift in reading habits. According to a poll done by the 
UK's National Literacy Trust, youngsters are more likely to possess a mobile phone than a book. According to the research, 85.5 percent of British youngsters aged 7 to 16 had a mobile phone, compared to 72.6 percent who owned a book (Paton, 2010).

According to an assessment of past studies, the world is undergoing a paradigmatic change away from print and toward screen media consumption. Everyone has been impacted by information and communication technology applications. The expansion of broadband networks and the rise in the number of Internet users over the past decade have impacted those involved in the information industry. The availability and ease of access to information provided by intelligent devices have impacted the behaviour of information consumers, particularly young people, all over the world.

\section{Dwindling reading culture in the internet era}

Especially in this day and age of Internet proliferation, technology is slowly but steadily taking over control of individuals' lives, and the desire to read is dwindling by the day (Igbokwe, 2012). Instead of enhancing the reading experience, it has slowed the reading enthusiasm of Pakistanis, particularly youngsters. A year-old child, for example, prefers skimming on a handset over reading picture books because of the growing amount of digital information media (Facebook, email, myspace, togo.com, youtube, whatsapp.com, LinkedIn, wikis, blogs, Twitter, etc.) available. He or she becomes accustomed to this behavior when he or she is three or four years old. Young individuals are also reported to be spending an increasing amount of time skimming and browsing the Internet and other electronic media, which has had a negative impact on the culture of lifelong reading among the general public.

According to Kojo, Agyekum, and Arthur (2018), university students' increased usage of social media has unquestionably altered their reading habits. As a result, the nature and goal of reading seem to stray from the reading techniques, which are short, linear, and less organized. All ages are less likely to read extensively in the hypertext environment because they cannot read profoundly. According to some academics, the proliferation of electronic media may negatively impact the capacity to read extensively and maintain a long-term reading habit (Liu, 2005: Ngugi \& Mberia, 2014). Human capital creation and the growth of knowledge and skills have been claimed to be linked to education as a bridge to the future, an agent for the construction of human capital (Adegbesan, 2011). Therefore, it is essential to emphasize that reading may improve education since it is intertwined with the whole educational process and therefore needs good reading to achieve educational success. It should be mentioned that the use of the Internet for educational purposes has several advantages, particularly in terms of worldwide relevance and currency. The employment of artificial intelligence as a replacement for decent reading skills, on the other hand, should raise red flags. The Internet seems to have diminished people's interest in reading printed books and their ability to build vocabulary, general knowledge, and a comprehensive perspective, all of which benefit from solid reading habits. With this in mind, it is essential that reading is regarded as a lifelong experience that should be embraced by people of all ages (whether they are infants, adolescents, adults, or the elderly), regardless of their cultural, social, political, or ethnic background. Furthermore, reading should not only be done to pass an examination but should be an enthusiastic habit for relaxation, enjoyment, general information, professional and personal development that will contribute to positive change in the lives of individuals rather than a rote habit for passing an examination (Ngugi \& Mberia, 2014) 
Following 0ji (2007)'s findings on social media habits of their wards, many parents, particularly those of secondary school students, are concerned about their wards' use of social media sites such as Facebook, Twitter, Instagram and telegram, palmchat, WhatsApp, and other social media sites because they believe that their wards lack sufficient time to read or concentrate on their studies. In particular, the increasing number of university students who use the internet for social activities rather than academic objectives is concerning. Nkordeh et al. (2017) further said that it was a proven truth that Pakistani youngsters of today had lost interest in reading as a result of this. It is more common for them to spend countless hours on social media, talking with friends, perusing the internet, and doing various other activities. As a result, reading a book or any other written material seems to be an ancient concept for most teenagers (Eke, Omekwu \& Odoh, 2014). When Shehu and Shehu (2014) conducted a study on the challenges of social networking on students' reading habits at Ahmadu Bello University, Zaria, they discovered that whenever a picture was posted on Facebook, it received approximately 240 likes and 53 comments in 24 hours. In contrast, when an article was posted, it received only approximately 16 likes and 5 comments in the same 24-hour period. He was pretty concerned that so many teenagers were wasting their time scrolling.

\section{The imperative for lifelong reading in the internet era}

For reading to be worthwhile, young people must learn to read and develop reading habits that will serve them throughout their lives (Inderjit, 2014). Because of the rising quantity of digital information accessible and the increasing amount of time that individuals spend electronic reading media, the digital environment has started to impact people's reading habits and habits of reading. If you wish to keep anything from an African, a common phrase says, "hide it in a book." Despite the many advantages of the Internet, particularly in global relevance and currency, and the fact that it provides an almost limitless and vast amount of information resources, it appears to have decreased interest in reading printed materials, vocabulary development, and general knowledge in general. When compared to reading, web surfing and skimming have several drawbacks to consider. Furthermore, the Internet has done more damage to everyone's reading habits than good. Because it is not a well-organized collection, it takes time to identify and access information; in some instances, membership is necessary; there is no quality control, and there are very few historical items available.

According to Igbokwe et al. (2012), everyone must learn the fundamentals of reading and cultivate a reading culture throughout their lives to thrive in life. Not only that, but reading should not be limited to a specific period in one's life but should be an activity that one engages in throughout one's whole life. Another ludicrous argument in this direction is that the introduction of electronic and digital libraries via the internet, rapidly replacing formal reading, is a result of the internet. The availability of technology is a positive metric that should be given the attention it deserves. However, it cannot be used as a replacement for formal reading since, as compared to screen reading, one may read a book for many hours at a time without being fatigued. Ironically, even in the present sophisticated world, which is known as the advocate of modern technology, manual book reading is expanding, but in our country, the trend is eroding. By language experts, children possess varying degrees of language acquisition device (LAD). However, if they have solid study habits, they will be able to do well in academics and all other aspects of their lives, including relationships.

The educational community should adopt several policies and activities to foster the pragmatic evolution of a nation-wide reading culture to promote and expand students' 
knowledge of the importance of reading. When children observe adults reading, they are inspired to do the same. Teachers may inspire their pupils by acting as role models for them to follow. Improved methods for instilling a love of reading should also be implemented. For students who often utilize the library for individual reading, teachers who regularly bring their classes to the library for skill sessions and topic area research may cultivate their interests. To encourage students to read and write more often, teachers may use various practical instructional tools to get them into the habit of doing so. In addition to this, pupils should be encouraged to read aloud throughout the class. Students' reading skills improve due to trips to the library, where they may choose books on topics that interest them. There should be a librarian on staff at every school to ensure that the library functions appropriately. As a part of the school day, students should have time to read in the library. Time for reading should be accounted for in the institution's schedule by its leaders. Teaching reading as a distinct topic in schools should also be encouraged (Akbar, 2020; Asif et al. 2022).

Students who excel in reading and writing should get rewards from their school libraries regularly, such as prizes. The internet and digital libraries must be made available to students in schools. As a result, they would have more access to cutting-edge information. Students should have access to a wide range of reading materials, including novels, newspapers, and periodicals, during their free time. In this aspect, parents play a critical role. A reading-friendly setting in the home may help parents encourage their children to read. They should also be able to maintain a library at home that is well-stocked with children's books. The time has come for a fresh start and an evolution of the reading culture from elementary school to our nation's most prestigious colleges and institutions. Teachers, professors, and other education professionals have the primary responsibility in this respect; as role models, they must do all in their power to encourage their pupils to follow in their footsteps. Non-governmental groups and the government should provide significant sums to equip schools with libraries and require all pupils to take required library classes to instill reading habits in them. An adequate system of assessment and evaluation must be implemented after that. Aside from that, substantial public awareness efforts and the development of community public libraries should be conducted immediately. In order to improve quality education and to read culture, we need to expand this culture as quickly as possible.

\section{Conclusions and recommendations}

Different issues related to promoting reading culture among Pakistani library patrons were discussed in this study, which revealed a pressing need to develop a reading culture in the society as a whole in order to maintain reading habits and ensure that the society is wellliterate in all areas of subjects, as well as to use reading in everyday life. In addition, the findings of this study suggested that different roles of libraries should be developed to develop a reading culture in society. These roles include changing the services, products, and atmosphere to meet the current demands of readers, particularly for schools, parents, and libraries, as well as developing effective education policies. The employment of these techniques is beneficial in fostering reading habits, but they are also capable of meeting the complicated information demands of users and exceeding their information expectations.

Given that the Internet is a primary source of information for students, they should get basic information literacy teaching to use credible sources of information. Additionally, the data indicated that pupils read both on-screen and on paper. As a result, libraries should concurrently create screen-based reading services in addition to conventional resources. To 
eliminate distractions (through pop-ups/links) and to address expense concerns associated with onscreen reading, school libraries may supply e-devices loaded with current and most recent electronic copies of needed books/reading material. Because Generation Z students like paper, conventional libraries should make an effort to recruit this generation. The library atmosphere should be inviting and accommodating book lending rules, and book banks may assist students in borrowing print books from libraries. Collections focusing on users should be produced. The current study's results demonstrated that parents and instructors stimulate pupils to read in print format, demonstrating their impact and involvement.

Additionally, a designated period should be set out for students to interact with library resources, and instructors should assign tasks that allow for the utilization of library resources and services. Parents may also help increase library usage. They should prioritize time management and bring their children to public libraries. This will foster children's reading habits and educate them about the library's resources. Given that prior research has shown that the local/native language is critical for successful learning (UNESCO, 2008), and students have expressed a need for knowledge in international and local languages, libraries should construct demand-driven collections.

The production of indigenous literature may get special attention, or the literature in demand may be translated into the local tongue if it is not already available. Students' IQ levels are raised as a result of their everyday knowledge. It was shown that semi-government school pupils had a much lower interest in common knowledge than other students. Special activities (such as quiz contests) should be arranged to engage pupils in daily knowledge, as recommended. Because female students spend more time reading than male students, additional activities should promote a reading culture on male college campuses. Unique collections in the local language may be presented to pupils in upper secondary school grades since they are more predisposed to reading materials written in the Urdu language. The results and implications of the research may also be of use to school administrations and libraries in other developing nations in formulating appropriate policies for their environments. It is essential to mention that lifelong reading stimulates the mind and creativity, aids in job growth, improves one's language and vocabulary, keeps one up to date with current events, and aids in relaxing and rejuvenating the mind, among other benefits. Reading will never be able to replace skimming and to surf the Internet for information completely. A lifetime reading habit is essential for achieving overall success in life. As a result, it must be practiced throughout one's life.

The commonly held belief that reading in Pakistan is declining as a result of the widespread use of intelligent devices (Daily time, 21 January 2014; Dawn, 31 July 2012; Gallup Pakistan, 2011) is not valid for students, who reported that the amount of time they spent on reading was more significant when compared to the amount of time they spent on reading five years ago. It was alleged that they had electronic gadgets in their possession and were acquainted with the functions and procedures related to the on-screen reading material. Even though they preferred to read in print format, in reality, they relied more on digital information sources. The government and private organizations should work together to increase the number of libraries in Pakistan to encourage the culture of book reading. They will develop reading habits if they instill in themselves and sit with their children to participate in book reading sessions with youngsters. "What the kids see is what they learn." Libraries and library staff must adapt to young students' changing tastes to fulfill their responsibilities effectively. Marketing books, whether for adults or children, is a formidable task in this day and age. 
Students might be inspired to read by a passionate librarian who is committed to their success. However, the majority of schools do not have a library. The few schools that do have one do not always have a librarian on staff, and the volumes sit on the shelf, collecting dust.

\section{References}

Adegbesan, S. O. (2011) Establishing quality assurance in Nigerian education system: Implication for educational managers. Educational Research and Reviews, 6(2), 147-151.

Adnan, A., Akram, F., \& Akram, A. (2016). Identification of Factors Promoting Reading Habits of Students: A Case Study on Pakistan. Research on Humanities and Social Sciences, 6(17), 56-62.

Ahmad, H. I., Malik, K., \& Azeem, M. (2014). A Study of Reading Habit and Computer Technology Effect on Student in Pakistan. Journal of Education and Literature, 1(1), 9- 19.

Ahmed, M. S. (1964). Reading habits of men in West Pakistan. National Book Centre of Pakistan: Karachi.

Ahuja, K.K., Mishra, B., Goyal, H. (2010). Reading habits in digital environment. International Research Journal, 12(1): 28-31

Akbar, P. K. (2020, November 7). The falling culture of reading. The News. Retrieved November 18, 2021, from https://www.thenews.com.pk/magazine/us/746031-the-falling-cultureof-reading.

Ali, S. (2017, April 24). USAID promoting reading culture in Pakistan. The Nation. Retrieved November 18, 2021, from https://nation.com.pk/25-Apr-2017/usaid-promoting-readingculture-in-pakistan.

Ansari, S., Panhwar, A. H., \& Umrani, S. (2016). Investigating ESL learners' reading habits in a Pakistani university. ELF Annual Research Journal, 85-102.

Applegate, A. J., \& Applegate, M. D. (2004). The Peter effect: Reading habits and attitudes of preservice teachers. The Reading Teacher, 57(6), 554-563.

Asif, M., Yang, L., Ali, M., \& Hashim, M. (2022). An Analytical Overview of Book Publishing and Copyright Issues in Pakistan. International Journal of Instructional Technology and Educational Studies, 3(2), 1-13.

Asif, M., Ali, M., M’Begniga, A., Guoqing, Z., Yang, L., \& Hashim, M. (2021). China-Pakistan Economic Corridor: Analytical overview on Socio-Cultural Romance between China and Pakistan. Randwick International of Social Science Journal, 2(4), 492-508.

Awais, S., \& Ameen, K. (2013). The reading preferences of primary school children in Lahore. Pakistan Journal of Library and Information Science, 14: 38-43. Retrieved on 15 April 2014 from http://pu.edu.pk/images/journal/pjlis/pdf/7th\%20Paper_v_14_13.pdf

Balakrishnan, V., \& Gan, C. L. (2016). Students' learning styles and their effects on the use of social media technology for learning. Telematics and Informatics, 33(3), 808-821.

Batool, S. H., \& Mahmood, K. (2016). Teachers' conceptions about information literacy skills of school children. Pakistan Journal of Information Management \& Libraries (PJIM\&L), 13, 1-6.

Bodomo, A, Lam, M., \& Lee, C. (2003). Some students still read books in the 21st century: A study of user preferences for print and electronic libraries. The Reading Matrix, 3(3), 34-49.

Bruning, P. F., Alge, B.J., Lin, H.-C. (2018). The embedding forces of network commitment: An examination of the psychological processes linking advice centrality and susceptibility to social influence. Organizational Behavior and Human Decision Processes, 148, 54-69.

Burgess, S. (2005). The preschool home literacy environment provided by teenage mothers. Early Child Development and Care, 175(3), 249-258. 
Burgess, S. R., Sargent, S., Smith, M., Hill, N., \& Morrison, S. (2011). Teacher's leisure reading habits and knowledge of children's books: Do they relate to the teaching practices of elementary school teachers? Reading Improvement, 48(2), 88-102.

BusinessDictionary.com. (2014). Retrieved on 22 April 2014 from http:// www.businessdictionary.com/definition/Generation-Y.html

Camp, D. (2007). Who's reading and why: Reading habits of 1st grade through graduate students. Reading Horizons, 47(3), 251-268.

Chettri K. and Rout S. K. (2013). Reading habits: An Overview. Journal of Humanities and Social Science, 14(6), 13-17.

Chokron, S., \& De Agostini, M. (2000). Reading habits influence aesthetic preference. Cognitive Brain Research, 10(1-2), 45-49.

Clark, C. \& Akerman, R. (2006). Social inclusion and reading - an exploration. London: National Literacy Trust.

Clark, C., Osborne, S., \& Akerman, R. (2008). Young people's self-perceptions as readers: An investigation including family, peer and school influences. London: National Literacy Trust.

Cull, B. W. (2011). Reading revolution: Online digital text and implications for reading in academe. First Monday, 16(6). Retrieved on 13 April 2014 from http://firstmonday.org/ojs/index.php/fm/ar ticle/ view/3340/2985\#author

Cumaoglu, G., Sacici, E., \& Torun, K. (2013). E book versus printed materials: Preferences of University students. Contemporary Educational Technology, 4(2), 121-135.

Daily Time [Pakistan]. (2014, January 21). Habit of book-reading declining among youth. Retrieved on April 25, 2015 from http://www. dailytimes.com.pk/islamabad/21-Jan2014/habit-of-book-reading-declining- among-youth

Davidovitch, N. \& Yavich, I. R. (2016). Don't throw out paper and pens yet: On the reading habits of students. Journal of International Education Research, 12(4), 129-144.

Dawn. (2012). Encouraging reading habit. Retrieved on January 20, 2015 http://www.dawn.com/news/738521/enco uraging-

Dent, V. F. (2013). A qualitative study of the academic, social, and cultural factors that influence students' library use in a rural Ugandan village. The International Information \& Library Review, 45(1), 37-49.

Dilshad, M., Adnan, A., \& Akram, A. (2013). Gender Differences in Reading Habits of University Students: An Evidence from Pakistan. Pakistan Journal of Social Sciences, 33(2), 311-320.

Dodici, B. J., Draper, D. C., \& Peterson, C. A. (2003). Early parent-child interactions and early literacy development. Topics in Early Childhood Special Education, 23(3), 124-136.

Doiron, R. (2003). Motivating the lifelong reading habit through a balanced use of children's information books. School Libraries Worldwide, 9(1), 39-49.

Doiron, R. (2011). Using e-books and e-readers to promote reading in school libraries: Lessons from the field. In IFLA Conference (pp. 13-18). Available on: https://www.ifla.org/pastwlic/2011/143-doiron-en.pdf

Dorothy, R. (2002). Diagnosis and correction in reading and guiding reading instruction, (4th ed.) Boston: Allyn and Bacon.

Eisemon Thoma Owen. (1997). Literacy, social factors and consequences. In Middletown, J. (Ed), Encyclopedia of Africa South of the Sahara, Vol. 2. New York: Charles Scribner's Sons.

Eke H, Omekwu C \& Odoh J. (2014). The use of social networking sites among the undergraduate students of University of Nigeria, Nsukka. Library Philosophy and Practice (e-journal). Libraries at University of Nebraska-Lincoln. 
Fabunmi, F. A., \& Folorunso, O. (2010). Poor reading culture: A barrier to students' patronage of libraries selected secondary school in ado local government area of Ekiti-State, Nigeria. African Research Review, 4(2).

Farver, J. A. M., Xu, Y., Eppe, S., \&Lonigan, C. J. (2006). Home environments and young Latino children's school readiness. Early Childhood Research Quarterly, 21(2), 196-212.

Feitelson, D., \& Goldstein, Z. (1986). Patterns of book ownership and reading to young children in Israeli school-oriented and nonschool-oriented families. The Reading Teacher, 39(9), 924-930

Ferguson C. (2008). Technology left behind - the Kindle fire still burns. Against the Grains, $20(5), 88-9$.

Gambrell, L. B. (2011). Seven rules of engagement: What's most important to know about motivation to read. The Reading Teacher, 65(3), 172-178.

Ghaffar, A. (2018). Reading Habits Among Undergraduate Students of NED University of Engineering and Technology, Karachi, Pakistan: A Pilot Study. Library Philosophy and Practice, 1.

Goulding, A. (2002). Public libraries and reading. Journal of Librarianship and Information Science, 34(1), 1-3.

Greaney, V. (1986). Parental influences on reading. The Reading Teacher, 39(8), 813-818.

Hansen, H. S. (1969). The impact of the home literary environment on reading attitude. Elementary English, 46, 17-24.

Hartas, D. (2012). Inequality and the home learning environment: predictions about sevenyear- olds' language and literacy. British Educational Research Journal, 38(5), 859-879.

High, P., Hopmann, M., LaGasse, L., \& Linn, H. (1998). Evaluation of a clinic-based program to promote book sharing and bedtime routines among low-income urban families with young children. Archives of Pediatrics \& Adolescent Medicine, 152(5), 459-465.

Hopper, R. (2005). What are teenagers reading? Adolescent fiction reading habits and reading choices. Literacy, 39(3), 113-120.

Hung, C. L. \& Majoribanks, K. (2005). Parents, teachers, and children's school outcomes: A Taiwanese study. Educational Studies, 31(1), 3-13.

Hussain, I., \& Munshi, P. (2011). Identifying reading preferences of secondary school students. Creative Education, 2(05), 429-434.

Igbokwe et al. (2012). The influence of electronic media on reading ability of school children. Library Philosophy and Practice. Available at http://unllib.unl.edu/LPP/

Inderjit, S. (2014). Reading trends and improving reading skills among students in Malaysia. International Journal of Research in Social Sciences, 3(5), 70-81

Jabbar, A. (2015). Role of school teacher in promoting reading habit among school children: $A$ study of private school systems of Lahore. M. Phil. Thesis, Department of Library and Information Science, University of the Punjab, Lahore, Pakistan.

Jamali H. R., Nicholas D., \& Rowlands I. (2009). Scholarly e-books: The views of 16,000 academics: Results from the JISC national e-book observatory. Aslib Proceedings, 61(1), 3347.

Kaufer, D., Gunawardena, A., Tan, A., \& Cheek, A. (2011). Bringing social media to the writing classroom: Classroom salon. Journal of Business and Technical Communication, 25(3), 299321. 
Kavi K., Tackie N. B. and Bugyei A. (2015). Reading for pleasure among junior high school students: Case study of the Saint Andrew`s Anglican Complex Junior High School, Sekondi. Library Philosophy and Practice, 12-34.

Khan, N. (2017). How to develop reading habits among children. Pakistan Library and Information Science Journal, 48(4), 115-116.

Kim, T. T., Karatepe, O. M., Lee, G., \& Demiral, H. (2018). Do gender and prior experience moderate the factors influencing attitude toward using social media for festival attendance? Sustainability, 10(10), 3509.

Kim, Y. S. (2009). The relationship between home literacy practices and developmental trajectories of emergent literacy and conventional literacy skills for Korean children. Reading and Writing, 22(1), 57-84.

Kimme Hea, A. C. (2014). Social media in technical communication. Technical Communication Quarterly, 23(1), 1-5.

Kojo, D. B., Agyekum, B. O., \& Arthur, B. (2018). Exploring the effects of social media on the reading culture of students in tamale technical university. Journal of Education and Practice, 9(7).

Liu, Z. (2005). Reading behavior in the digital environment: changes in reading behavior over the past 10 years. Journal of Documentation, 61(6), 12.

Kush, J. C., \& Watkins, M. W. (1996). Long-term stability of children's attitudes toward reading. The Journal of Educational Research, 89(5), 315-319.

Law, K. M., Geng, S., \& Li, T. (2019). Student enrolment, motivation and learning performance in a blended learning environment: The mediating effects of social, teaching, and cognitive presence. Computers \& Education, 136, 1-12.

Lee, A. R., \& Horsley, J. S. (2017). The role of social media on positive youth development: An analysis of 4-H Facebook page and 4-H'ers' positive development. Children and Youth Services Review, 77, 127-138.

Liang, Y., Zheng, X., Zeng, D. D., Zhou, X., Leischow, S. J., \& Chung, W. (2015). Characterizing social interaction in tobacco-oriented social networks: An empirical analysis. Scientific Reports, 5(1), 1-11.

Lijuan, S. (2007). An introduction to the experiences of popularization activities of reading in Hong Kong and Macao. Library Journal (China), 25(5). Available on: http://en.cnki.com.cn/Article_en/ CJFDTotal-TNGZ200705018.htm.

Linnakyla, P., Malin, A., \& Taube, K. (2004). Factors behind low reading literacy achievement. Scandinavian Journal of Educational Research, 48(3), 231- 249.

Longo, B. (2014). Using social media for collective knowledge-making: Technical communication between the global north and south. Technical Communication Quarterly, 23(1), 22-34.

Lyytinen, P., Laakso, M. L., \& Poikkeus, A. M. (1998). Parental contribution to child's early language and interest in books. European Journal of Psychology of Education, 13(3), $297-$ 308.

Mahmood, K. (2004). Libraries and promotion of reading habits in the digital age. Pakistan Library Information Science Journal, 35(3), 18-24.

Makenzi, M. (2004). Reaching out to the less advantaged: reading tents in Kenya. World library and information congress: 70th IFLA General Council. Available at: http://www.ifla.org/iv/ifla 70/ prog04 .html. [Cited 16th June 2005] 
McKool, S. S., \& Gespass, S. (2009). Does Johnny's reading teacher love to read? How teachers' personal reading habits affect instructional practices. Literacy Research \& Instruction, 48, 264-276.

McSwain, B. (2008). Bringing it all together: Salisbury reads. APLIS, 21(2), 62-65.

Nair, H. S., Manchanda, P., \& Bhatia, T. (2010). Asymmetric social interactions in physician prescription behavior: The role of opinion leaders. Journal of Marketing Research, 47(5), 883-895.

Naveed, M. A., \& Ameen, K. (2015). Reading Habits and Behavior of Information Professionals in the Digital Era. Pakistan Library \& Information Science Journal, 46(3), 66-78.

Netten, A., Voeten, M., Droop, M., \&Verhoeven, L. (2014). Sociocultural and educational factors for reading literacy decline in the Netherlands in the past decade. Learning and Individual Differences, 32, 9-18.

Ngugi, M. N. \& Mberia, H. K. (2014). The influence of the internet surfing on the reading culture of secondary school teachers: A Case study of newspaper readership in Kigumo Sub County, Kenya. International Journal of Academic Research in Business and Social Sciences, 4(11), 96110.

Oji, R (2007). Reading Habit among Nigerian Youth. Nigerian Library link, 5(1), 93-100.

Nichols, S. (2000). Unsettling the Bedtime Story: parents' reports of home literacy practices. Contemporary Issues in Early Childhood, 1(3), 315-328.

Nkordeh, N. et.al. (2017). Impact of Social Media on The Reading Culture of Nigerian Youths; Is the Social Media platform providing an Alternative Source of Education? Proceedings of the World Congress on Engineering and Computer Science: 1, October 25-27, San Francisco, USA

Ogunrombi, S. A., \& Adio, G. (1995). Factors affecting the reading habits of secondary school students. Library review, 44(4), 50-57.

Oyelude, A. A. (2013). Teachers'/students' library use and reading habits in Ido local government area, Ibadan, Nigeria. School Libraries Worldwide, 19(2), 69-80.

Palmer, T. (2008). Reading the game: Using sport to encourage boys and men to read more. APLIS, 21(2), 78-83

Pattuelli M. C. and Rabina D. (2010). Forms, effects, function: LIS students' attitudes towards portable e-book readers. ASLIB Proceedings, 62(3), 228-244.

Robinson, H. A. (1979). Preparing teachers of reading in the United States. California Journal of Teacher Education, 6(3), 1-11.

Rosenberg D (2000). The research: rationale, methodology, limitation. In Rosenberg, D. (Ed.), Books for schools: improving Access to supplementary reading materials in Africa. London: Association for the Development of Education in Africa.

Scher, D., \& Baker, L. (1994). Attitudes toward reading and children's home literacy environments. Retrieved from https://archive.org/details/ERIC_ED418767

Schlereth, C., Barrot, C., Skiera, B., \& Takac, C. (2013). Optimal product-sampling strategies in social networks: How many and whom to target? International Journal of Electronic Commerce, 18(1), 45-72.

Shahid, A. (2015). Reading habits of Karachi Journalists. Pakistan Library and Information Science Journal, 46(2), 34-42.

Shaikh, N. A. (2019, November 24). The diminishing reading habits in Pakistan. Retrieved November 18, 2021, from https://www.pakistangulfeconomist.com/2019/11/25/thediminishing-reading-habits-in-pakistan/ 
Shapiro, J., \& Whitney, P. (1997). Factors involved in the leisure reading of upper elementary school students. Reading Psychology: An International Quarterly, 18(4), 343-370.

Shehu, N \& Shehu, A. (2014) Challenges of Social Networking on Students' Reading Habit in Ahmadu Bello University, Zaria. Research on Humanities and Social Sciences, www.iiste.org, 4(19).

Smith, R., \& Young, N. (2008). Giving pleasure its due: Collection promotion and readers' advisory in academic libraries. Journal of Academic Librarianship, 34(6), 520-526.

Soroya S. H. and Ameen K. (2018). What do they want? Millennials and role of libraries in Pakistan. The Journal of Academic Librarianship, 44(2), 248-255.

Soroya S. H., \& Ameen K. (2020) Millennials' Reading behavior in the digital age: A case study of Pakistani university students. Journal of Library Administration, 60(5), 559-577.

Soroya, S. H., \& Ameen, K. (2016). Reading Trends of Youth in Pakistan: A pilot study. Pakistan Journal of Information Management \& Libraries, 17, 86-96.

Stathopoulou, A., Siamagka, N. T., \& Christodoulides, G. (2019). A multi-stakeholder view of social media as a supporting tool in higher education: An educator-student perspective. European Management Journal, 37(4), 421-431.

Trott, B., \& Elliott, J. (2009). Barriers to extracurricular reading promotion in academic libraries. Reference \& User Services Quarterly, 48(4), 340-346.

Wang, J., Aribarg, A., \& Atchadé, Y. F. (2013). Modeling choice interdependence in a social network. Marketing Science, 32(6), 977-997.

Wawire F (2007). Cultivation and promotion of a reading culture in urban areas: A case study of schools in Eldoret Municipality. Thesis (M Phil), Moi University Eldoret.

Weller M. (2011). Digital scholars: How technology is transforming scholarly practice. London: Blooms bury Academy.

Yusof, N. M. (2010). Influence of family factors on reading habits and interest among level 2 pupils in national primary schools in Malaysia. Procedia Social and Behavioral Sciences, 5, 1160-1165.

Zia, M. W. \& Samreen, N. (2017). Reading habits of faculty members of Dadabhoy Institute of Higher Education (DIHE). Pakistan Library and Information Science Journal, 48(4), 16- 20.

\section{Contact}

Dr. Muhammad Asif

School of Journalism \& Communication

Hunan Normal University Changsha

Hunan

China

asifanu@hotmail.com 